3. Застосування МК спрошує кінематику ЛЗЕТ, підвишує економічність. Електромобіль стає набагато простішим і дешсвшим в експлуатації, оскільки містить менше механічних вузлів. Процес розгону електромобіля здійснюеться плавно без перемикання коробки передач.

\title{
Література
}

1. Будніков В.М. Гібридна система слектроживлення з інерційним накопичувачем снергії для спеціалізованих видів транспорту: Авторсф. дис.. канд. техн. наук: 05.09.03/ Кременчуцький держ. пглітсхніч. ун-т ім. М. Остроградсыкого. - Кременчук, 2009. - 18 с.

2. Вершинин Д.В., Водичев В.А., Войтенко В.А., Смотров Е.А., / Особенности выбора параметров бортового источника питания электротранспортного средсгва. // Електромашинобудування та електрообладнання. К.: Техніка. - 2008. - Brп. 71. - C. 5-11.

3. Вершинин Д.В., Войтснко В.А., Смотров Е.А., Николснко А.Н, Процерова Н.А. / Электропривод моторколеса электротранспоргного средства, // Електромашинобудування та електрообладнання. - К.: Техніка. 2009. - Вип. 74. - С. 25 - 30.

4. ЗАО НПП «Инкар». Мотор-колёса для электромобнпей. http://inkar.mccinet.ru

УДК 65.011. 56:004.032.26:004.8

\section{НЕЙРОННЫЙ РЕГУЛЯТОР В ПРОГРАММНОЙ СРЕДЕ КОНТРОЛЛЕРОВ КОНТАР}

\author{
Горпиняк Ю.ІІ, магистр; Пав.пов А.И., к.т.н., доцент \\ Одеская национыьная академия пипевњх технологий, г. Одесса
}

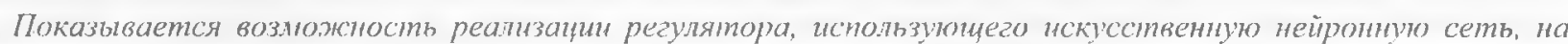
коніпролиере MC5 M3TA.

It shows the possibility of the constructing control, using an artificial neural network on the controller MC5 MZTA

Ключевые слова: нейрон, регулятор, контар, оптимнзация, контролер.
\end{abstract}

Искусственнље нсйронные сети (ИНС) находят все болес широкое прнменение в задачах автоматического регулирования. В настоящее время построение САР с классичсским линейным ПИД алгоритмом регулирования обычно сопровождается использованием той или иной методики самонастройки его параметров. Точно также и в случае использования ИНС для реализации алгоритмов регулироваєия необходимо прнменять слециальные методы настройки («обучения», «тренировки») параметров НHC.

Нзвестны два вида настройки параметров сети: самообучение и контролируемое обучение. Первый способ применяют в задачах распознавания образов и кластеризации, а второй - в задачах управления. Нз двух разновидностей контролируемого обучения (прямое контролируемое обучение и стимулируемое обучение) нанболее подходящим для использования в задачах регулирования является система стимулированного обучения. В ней обучаемой частью САР является нейронный регулятор, а объект регулирования, внешние воздействия (координатные возмущения, изменения сигната от задатчика и его производная. сигнал динамической ошибки и его производная) выступают в качестве окружающей среды. Стимулируемое обучение осушествляется по результату оценки осуществляемого ННС (регулятором) преобразования «вход-выход). Оценку результата вцполняют после подачи на вход ИНС тренировочного воздействия и затем изменяют настройку параметров сети так, чтобы максимизнровать скаляный индекс оценки, называемый стимулом (в психологии он известен как закон действия («проб и ошибок») Торндайка).

Для оптимизации параметров ПИД-алгоритмов регулирования широко применякт симплекс-метод Нелдера-Мида, который также можно отнести к методу стимулируемого обучения. И хотя в ПИД- алгорнтмс количество оптимизируемых параметров равно трём, тем не менее, как показывает опыт, указанныци симплексметод с успехом может быть нспользован и для расчета параметров ИНС, состояшей нз нсбольшого числа нейронов, распределенных по нескольким слоям [1,2]. Однико следует отметить, что нмеется суцественная проблема, которая всегда возникает при использовании любых известных методов настройки ИНС, состоящая в том, что число локальных опимумов, даже в вариантах ИНС с малым числом нейронов, очень велико. Это означает, что результат «обугения) ИНС в определяюшей мере зависит от удачного (именно так) выбора стартового набора козффициентов синаптических связей в ИНС, а также зависит от удачного выбора диапазонов их допустимых изменений. При неудачном выборе набора коэффицлентов обучение ИНС зайдет в тупик в окрестности одного локального оптимума, даже если рядом есть глобальный оптимум. При неудачном выборе диапазонов изменений коэффнциентов в ходе обучения ННС могут возникнуть ситуации, когда значение одних коэффнциентов обрашаются в ноль, а других сгремsтся к бесконечности и ири этом оптимум не достигается. 
Поскольку расчет величин коэффициентов синаптических связей обыгно выполнягот на персональных компьютерах, то для сокрашения необходимого для этой цели машинного времени рекомсндуем ограничиваться малыми размерами НHC с чнслом промежуточных слоев от двух до четырёх. Опыт показывает что наюболее эффективнымн для решения задачи построения САР является размещение большей часть нейронов именно в первом промежуточном слое. В отношении структуры вектора входных сигналов обрабатываемых ИНС, то в него рекомендуем в первую очередь включить сигналы: задания, регулируемой переменной, динамической ошибки, ее первой производной, основного координатного возмушения и егс первой производной. Кроме этих сигналов можно использовать сигналы второй производной от динамической ошибки и основного координатного возмуцения. А также, если пмеется, дополнительное координатногс возмущения, и его первую и вторую пронзводные. В качестве дополнительного координатного возмущения например, может выступать сигнал от другой (сепаратной) части многомерной САР, в состав которой входит интсресующий нас контур регулнрования.

Проектирование рсальной САР с нейронного регулятором состоит из двух этапов.

Первый этап - расчет коэффишиентов синаптических связей нейросети на компьютере в среде, например Matlab 5.2 с использованием пакетов программ Simulink.

Примером эффективного решения задачи регулирования может быть использование ИНС со структурой приведенной на рис. 1

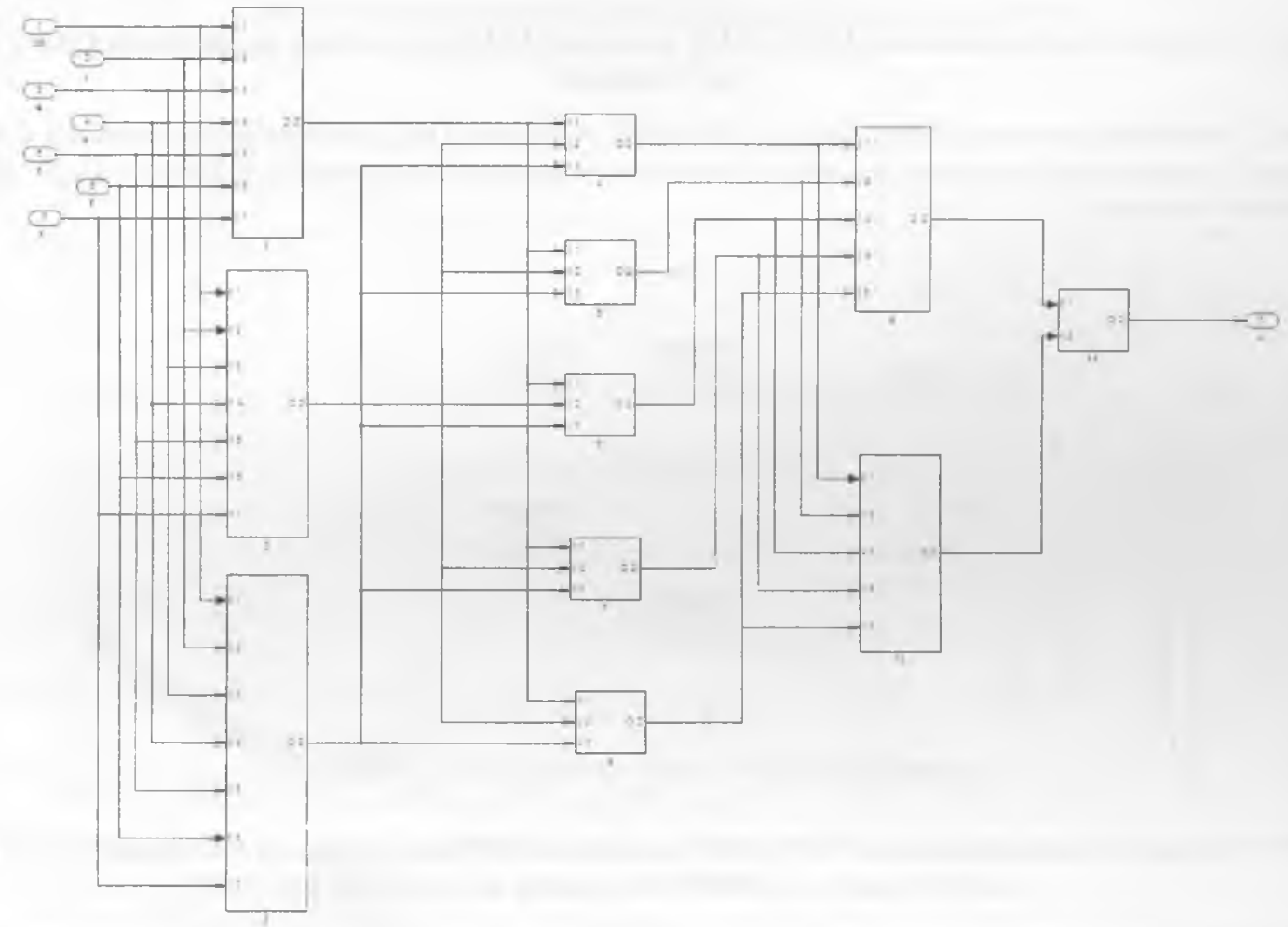

Рнс. 1 - Структура ИНС

Приведенная на рисунке ННС состоит из 10 нейронов распределенных по 4-м слоям. В данном иримере использован всктор входных сигналов, включајоший ввод значения задания (zd), сигнала регулируемого парамстра объекта (у), сигнала рассогласования (е), сго первой производной (е.), согнала координатного возмущсния (f), сго первой (f.) и второй (f..) производных. На выходе ННС имесм сигнал (u) участвующий в вычислении уцравляюшего воздействия наряду с сигналами от И - составляющсй и Д - составляющей регулятора

В качестве модели объекта регулирования использована структура, соответствующая передаточной функции:

$$
W(p)=\frac{1.6 e^{-4 p}}{(10 p+1)^{2}}
$$

На рис.2. представлены графики переходных процессов, характеризуюшие изменение рсгулирусмого парамегра объекта вследствие измснения сигнала задания и координатного возмушения в линейной САР ПНД-алгоритмом регулирования и в САР, в структурах которых использованы ИНС. На рисунке обозначены: 1-регулируемый параметр линейной САР с ІІИД алгоритмом; 2- регулируемый параметр САР с НHC в составе ПНД регулятора; 3-нзмеряемые возмущения, действуюшие на САР. Как вндно по представленному рисунку САР, в структуре которой ислользована ИНС, работает значительно лучше, чем линейная САР, в частности меньше максимальное динамическое отклонение и время переходного процесса, при нензмснных параметрах объскта (при отсутствни параметрических возмушений). 


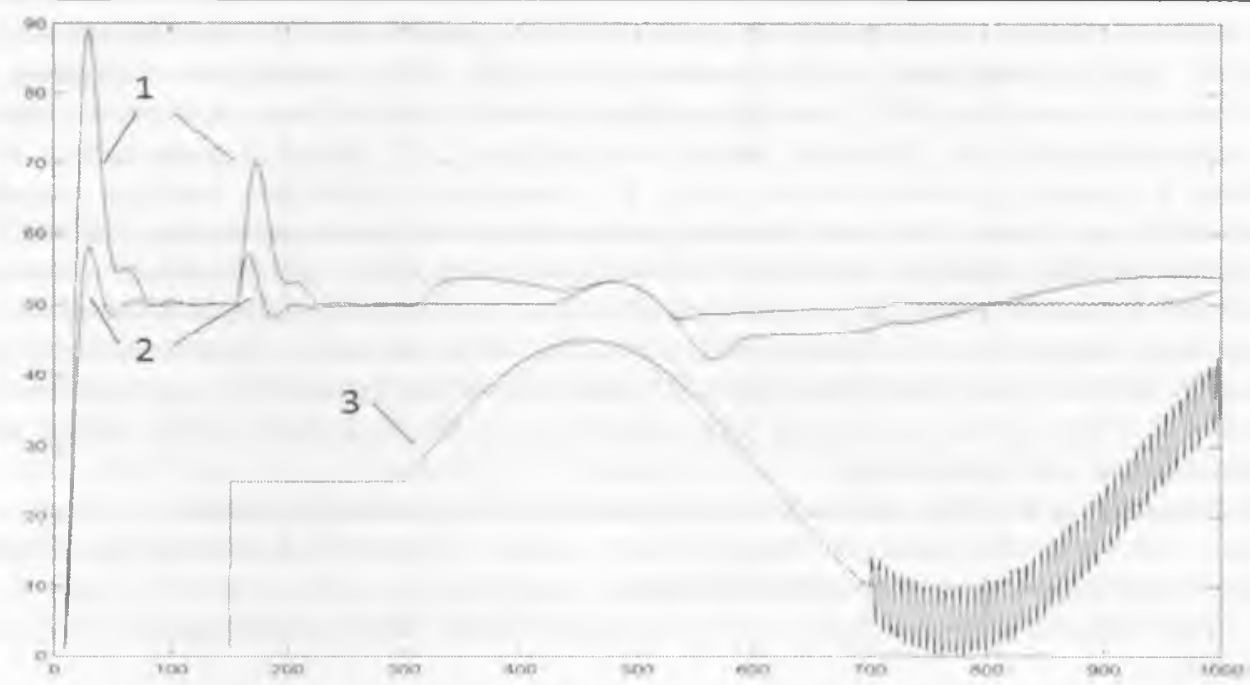

Рис. 2 - Результат моделирования САР с ИНС в составе ПИД регулятора и линейной САР с ГІИД регулятором

На рис.3. показана динамика обеих САР (САР с ИНС в составе ПИД регулятора и линейной САР с ПИД регулятором), отражаюшая действие на объект параметрических возмушений: $\mathrm{k}=2,6 ; \tau=8 ; \mathrm{T}=20$. Настройки регуляторов не менялись.



Рис. 3 - Результат моделирования САР с ИНС в составе ПИД регулятора и линейной САР с ПИД регулятором с параметри'ескими возмушениями

Второй этап - программная реализация нейронного регулятора в среде промышленного контроллера

При небольшом числе нейронов в ИНС, нейронный регулятор может быть программно реализован, например, гри использовании такнх контроллеров, как P-130, P-130Isa. МИК-51, МИК-52, Овен ПІЛК 150, комплекса контроллеров КОНТАР и др.

На рнс.4. показано окно проскта рсализации регулятора на контроллерс МС5, структура ИІІ которого соответствует рис.l., с ислользованием инструментальной системы программирования КОНГРАФ, разработанный для комплекса контроллеров КОНТАР (МС5, MC6, MC8, MC12)

Благодаря современному и удобному человеко-машинному интерфейсу, наличию большой и хорошо струкгурированной библиотеки программных модулей. поддержанных встроснной справкой, обеспечивастся легкое и быстрое освоение системы КОНГРАФ. Наличие симулятора позволяет осуществить отладку алгоритмов управления на стадии проектирования. Более того, имеется возможность моделирования замкнутых систем «регулятор-объект». Далее описана программная реализация регулятора, результаты симулирования приведены не будут

С помошью блока «ЗДН АН» вводится заданное значение, блок «Форм Вх Сигн» формирует сигналы, поступаюцие в ИНС, описаннъе выше. Содержимое блока представлено на рис.5.. Содержимое блока «ИНС», представленнос на рис.6. идентично представленному на рис.1.. Блоки «НАСЫШЕНИЕ», «УСИЛЕНИЕ», «СУММА» совместно реализуют нормирование сигнала управляющего воздействия.

Блок «Модель объекта» реализует модель об́ъекта согласно передаточной функции (1), а также модель исполнительного механизма н регулирующего органа. 




Рис.4 - Содержимое (программа) для контроллера МС5



Pис.5 - Содержимое блока «Форм Вх Сиги»



Рис.6 - Содержимое блока «ИНС» 
Нейронный регулятор в инструмснтальной системе КОНГРАФ вполне реализуем теми средствами, которые предоставдяет данная система, а именно при помоши обширной библиотеки, подлержанной справкой. ГІомимо реатизации самого регулятора имеется возможность реализации модели системы "регулятор-объект», с возможностьюее исследования в условиях действия координатных возмушений.

\title{
Литература
}

1. Павлов А.И. Нейронная система регулировачия высокой динамической точности//Наукові праці Одеської Національної Академії Харчових Технологій - Одеса: -2008.-Вип.33.-с. 64-69.

2. Павлов А.И. Нейронная сисгема регулирования// Наукові ираці Одеської Наніональної Академії Харчових Технологій - Одеса: -2007.-Вип.31.-Т.2.-с.72-77.

3. Каллан Р. Основные концепции нейронных сетей.-М.: «Вильямс». 2001.-288c.

\section{ИССЛЕДОВАНИЕ АЛГОРИТМОВ ТЕРМИНАЛЫНОГО УПРАВЛЕНИЯ МАНИПУЛЯТОРОМ С ЦИФРОВЫМ РЕГУЛЯТОРОМ СЕРИИ DGE-SP}

\author{
Деркунская В.О., аспнрант; Краснодуоеи Л.А., к.т.н., профессор \\ Севастопольский национальный технический университет, r. Севастополь
}

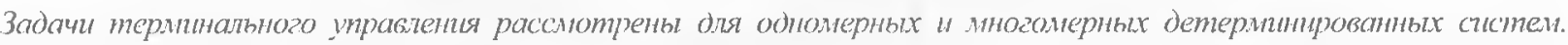

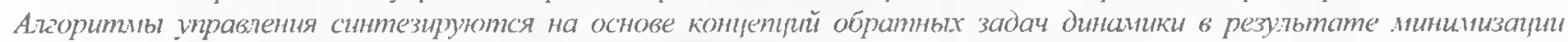



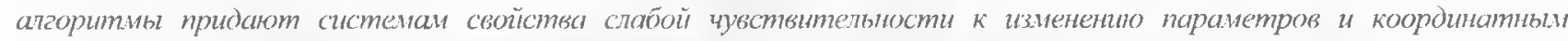

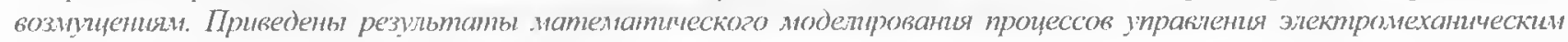
wanumysmopow.

Problems of termination control for one-dimensional and multidimensional state-determined systems are considered in the given article. Control algorithms are produced on basis of dynamics inverse problems' concepts in result of minimization of local functional in neighborhood of dedicated motion paths. It has been shown that produced algorithms add properties of weak vulnerability to parameters change and coordinate disturbance to the systems. The results of mathematical simulation of all-electromechanical manipulator's control process are also presented in the aricle.

Ключевые слова: терминальное управление, манипулятор, цифровой регулятор, алгоритм управления.

В технических прнложениях имеется важный класс задач, в которьх требуется перевести уиравляемый объект в назначенное состояние за конечный интервал времени. При этом критерием или показателем качества управления служит точность приведсния объекта в конечный момент времени. Такие задачи называются терминальными. Алгоритмы управления, обеспечиваюшие решение терминальньх задач, называют алгоритмами терминального управления.

Объектом исследования является система автоматического управления, манипулятор с цифровым регулятором серии DGE-SP, позиционирования каретки с заданными граничными условиями, представленный на рнс. 1

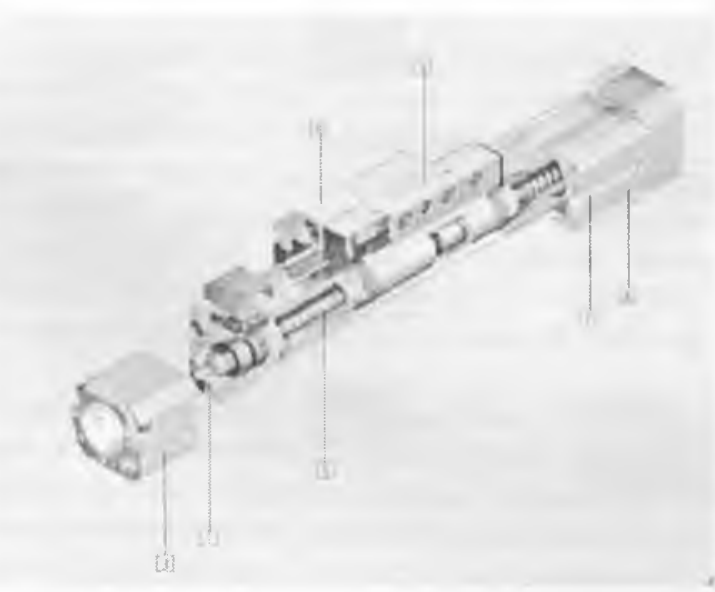

1- Винповой вал: 2-вал двигапеля; 3 - соединение с двиапелем; 4- анюминевый профиль; 5-карепка; 6-направляюипе карепки

Pис. 1 - Манипулятор серии DGE-18-SP 